\title{
USING INFORMATION VISUALIZATION TO Generate Student InTEREST IN Business Analytics: A Case Study
}

Reed H. McElfresh, Laurie A. Branch and Todd Palmer

Reed H. McElfresh (remcelfre@sbu.edu), MS MBA, St. Bonaventure University. Laurie A. Branch (lbranch@sbu.edu), PhD., St. Bonaventure University, Todd S. Palmer (tpalmer@sbu.edu), PhD., St. Bonaventure University.

Keywords: Business Analytics; Information Visualization; Fear of Math; Data Analytics; Bloom's Taxonomy; Data Story; Storytelling with Data

DOI: https://dx.doi.org/10.15239/j.brcadvje.2020.04.01.ja03

\begin{abstract}
The global economy is in the middle of a data revolution. In May 2018 , it was estimated that over $90 \%$ of the data in the world was generated in the previous two years (Marr, 2018). This unprecedented data revolution has created a need for business analysts to help companies monetize their data assets. The McKinsey Global Institute estimated that in the United States there would be a demand for two to four million "data translators" by 2026 (Henke et al., 2018). Data analysts and translators need a broad knowledge
\end{abstract}


base to process and interpret data; including a background in statistics. Unfortunately, many students struggle with statistics (Wang et al, 2018) and, in our experience, avoid classes that have a basis in mathematics. This case study outlines how the authors created an introduction to business analytics class utilizing information visualization to engage students and build their confidence before introducing applications of statistics they previously would have avoided. Results suggest that after students engaged with visualization, they were more willing to move outside their comfort zones and learn how to use software to perform statistical analyses.

\section{INTRODUCTION}

Business Analytics is a relatively new term that encompasses a number of educational disciplines. For the purposes of this paper, business analytics will be defined as "The use of data, information technology, statistical analysis, quantitative methods, and mathematical or computer-based models to help managers gain improved insight about their business operations and make better decisions" (Evans, 2016). Many of the core components have historically been covered in other courses in an undergraduate business curriculum including regression being covered in statistics courses, optimization in management science and Excel skills in business information systems courses (Wilder \& Ozgur, 2015). Other aspects, such as information visualization and data mining, are generally not covered in a specific courses. A course in business analytics packages all of these skills together and presents them to students in a comprehensive manner to give students the ability to analyze data and glean insights from the information produced to make better decisions.

In 2007, Davenport and Harris outlined the rise of business analytics and how different industries were implementing analytics into their workflows. In the discussion of future directions, the authors wrote that while there was a need for more analytic professionals, there was a much greater need for 'analytical amateurs' defined as people who "will have to have some understanding of how those analyses were performed and 
when they should be overridden." They concluded that colleges and universities should add additional analytic capabilities to their curricula (Davenport \& Harris, 2007).

Soon after the publication of Davenport and Harris' Competing on Analytics, many trade publication articles and books were published about the spread and benefit of analytics in business. For example the November 2013 and May 2015 cover stories of the Harvard Business Review were about making better decisions and the February 2016 cover story of the MIT Sloan Management Review was "How Technology is Transforming Management". The number of books on analytics is daunting with over 9000 results shown for search of books on analytics in Amazon, further demonstrating the popularity of the topic.

While it is clear that there is a need for more 'analytical amateurs' who would understand various methods of analyses, are able to interpret analytical outcomes, and who would feel comfortable questioning their results, getting buy-in from students is potentially more difficult. Many students express a fear of mathematics. A 2003 literature review identified statistical anxiety as an academically debilitating problem. This review found that "for many students, statistics is one of the most anxietyinducing courses in their programmes of study" (Onwegbuzie \& Wilson, 2003). For analytics, a discipline with a strong basis in statistics, this fear is problematic.

The case study begins with a review of the current landscape of business analytics education in higher education followed by an overview of how it was implemented at St. Bonaventure University and suggestions for other colleges looking to implement a course that is approachable to students who may not feel as though they can excel in a course with a basis in mathematics. 


\section{Business Analytics Teaching Background}

Following Davenport and Harris' advisory, business schools around the country began integrating analytics into their undergraduate curricula. In a 2016 publications, the AASCB stated that analytics is a key area of focus for a Bachelor's degree in business and that it was needed to strengthen accounting programs (Rienzo and Chan, 2018). The majority of schools offering business analytics by integrating the curriculum into existing courses in other disciplines or rebranding courses as business analytics (Wymbs, 2016). As of 2019, only $1.8 \%$ of AASCB colleges and universities offered data analytic degree programs at the undergraduate level (AASCB, 2019). For colleges implementing a business analytics education, there are three key items to consider: curriculum, teaching framework, and evaluation.

When developing an undergraduate business analytics curriculum, Rienzo and Chan identified three broad categories: analytical techniques, technical knowledge, and business knowledge. Analytical techniques included "problem solving skills, model building, and processes that can be applied to data to reveal trends and patterns", technical knowledge includes "means of preparing data for analysis and applying analytical techniques through computational tool mastery", and business knowledge "places data sets in context and connects the output of analyses to business strategy". Technical knowledge is often covered by teaching statistics software and data management, emphasizing spreadsheets, and data visualization. Analytic techniques include statistical methods including descriptive statistics, regression, and ANOVA, modeling and data mining. Business knowledge should include a focus on communication skills and practical experiences for students (2018).

Rienzo and Chan further identified four steps to build an appropriate teaching framework for the identified curriculum: (1) analytical techniques to apply to data, (2) technical knowledge of statistics and apply the analytical techniques, (3) an understanding of how these are used in industry, and (4) communication skills to explain or discuss the results of 
analysis in a business context. These should be applied in a manner that (1) targets specific levels of analytical knowledge, (2) cover techniques that can be used to provide insight on a broad range of business decisions and (3) be taught in a manner than the techniques can be understood (2018).

Cliff Wymbs at the Zicklin School of Business at Brauch College, NY, outlined five steps in evaluating a new business analytics program: (1) Develop new interdisciplinary courses that account for the broad background and applications of business analytics, (2) Align courses to be relevant to what business are looking for from new graduates, (3) Use real work projects to demonstrate the skills and thought processes they will need to excel upon graduation (4) capture the union of disciplines that use analytics to provide students with examples of analytics in as many courses as possible, and (5) strengthen faculty members' expertise in using analytics either through continuing education or by making analytical experience as a priority in the hiring of new faculty (2016).

\section{General Education Pedagogy - Bloom's Taxonomy}

Bloom's Taxonomy, one of the most frequently cited educational constructs, was originally conceived of as a framework for curriculum and test development (Seaman, 2010-11). Bloom himself remarked that "this taxonomy is designed to be a classification of the student behaviors which represent the intended outcomes of the educational process" (Bloom et. al. , 1956 p. 12 as cited in Seaman, 2010-11, p. 33). The initial review of the handbook took issue with some of the terminology used - a concern that continues today - but generally found value in the work for "all who are concerned with the behavioral goals for schools and colleges" (Coffman, 1956, p. 405 as cited in Seaman, 2010-11, p. 32). The second review in 1957 focused on the value of the taxonomy as a "tool for test development” (Stanley \& Bolton, 1957 as cited in Seaman, 2010-11, p. 32). However, the adoption and adaptation of Bloom's taxonomy turned out to be in its infancy. By the 1970's, the handbook was touted as "one of the major works in the field of Curriculum" (Sockett, 1971, p. 16 as 


\section{BRC Journal of Advances in Education Vol. 4, No. 1}

cited in Seaman, 2010-11, p. 33) and it remains extremely popular today. In his review of the evolution, revision, and use of Bloom's Taxonomy in the field of education, Seaman notes, "[a]s a tool for use in the fields of educational instruction, planning, and assessment, the taxonomy has few peers" (2011, p. 37).

The original Bloom's taxonomy provided detailed definitions for six cognitive categories that ranged from simple to complex. These six categories, which represent a hierarchy of cognitive applications from concrete to abstract, were expressed as nouns and included Knowledge, Comprehension, Application, Analysis, Synthesis and Evaluation (Krathwohl, 2002). The taxonomy was revised in 2001 in 12 ways, but the most relevant for our discussion is the revision in nomenclature. The six category descriptors were revised to be expressed as verbs: Remember, Understand, Apply, Analyze, Evaluate, Create (Krathwohl, 2002). As Seaman notes, "this emphasizes the active cognitive behaviors that are desired from a student, but also facilitates use by educators in designing and implementing curricula" (2011, p. 36).

According to Krathwohl, "Bloom saw the original Taxonomy as more than a measurement tool. He believed it could serve as a common language about learning goals to facilitate communication across persons, subject matter, and grade levels" as well as a "means for determining the congruence of education objectives, activities, and assessments in a unit, course, or curriculum..." (2002, p. 212). In this case study we hope to demonstrate the Taxonomy's usefulness in both ways as we endeavor to share with you -using the language of the Taxonomy - the evolution of our class curricula as well as how we applied the Taxonomy to increase our students' engagement with and mastery of the material by coaxing them along the hierarchy from simple to complex and concrete to abstract. 


\section{Case Write Up}

For the initial introductory Analytics course, we used a survey approach covering the topics shown in the table below. Given the number and breadth of the topics, we were able to only spend a day or two of class time on each. The breakdown of the coverage of material in class is presented in Table 1 . We discovered that the students could successfully parrot back the material we covered. This was evidenced by an average of $84 \%$ across the four exams given the first semester we taught the course with results from 38 students, an average of $87 \%$ across the 2 exams given the second semester we taught the course with results from 9 students, and an average of $77 \%$ across the two exams given in the third semester that we taught the course with results from 20 students. Scores on exams, out of class work, and in class observations revealed that their comprehension of the concepts and how to apply them was far stronger on the descriptive analytic elements as compared to the predictive and prescriptive analytic elements. This led us to conclude we were trying to cover too much material and that while the students were able to remember, and even understand the topics covered, we were falling short on helping them apply, analyze, evaluate, and create across all the areas that we were covering.

As we continued to refine what we included in and, perhaps more importantly, what we excluded from our analytics course, we realized we needed more than a single semester to do the material justice even at the survey level. The need for more time was magnified by our desire to include learning objectives that went beyond mere remembering to tap into all six levels of Bloom's taxonomy. Based on this finding, we decided to teach introductory and advanced analytics across two classes. To accomplish this, we assembled all the instructors and, with the guidance of the department chair, laid out all the topics that we would want to cover and then sequenced them to identify what topics belonged in which class. Our classes in the first three semesters had revealed that uninitiated students more easily grasped descriptive analytics over 


\section{BRC Journal of Advances in Education Vol. 4, No. 1}

predictive and prescriptive analytics so we decided to build the first class in the sequence around the general topic of analytics and big data with a focus on descriptive analytics. We moved predictive and prescriptive analytics into the advanced analytics class where effectively utilizing the more advanced tools used to perform each of these could be given greater attention. Table 2 shows the revised breakdown of the two course sequence and the tools used:

Removing the teaching of the tools to perform predictive and prescriptive analytics freed up several class sessions. We reflected on the parts of the course that students had the most positive reactions to in terms of actively engaging with the material and moving through at least the first five levels of Bloom's taxonomy on their own without much help from the instructors. The two areas that were most powerful in this regard were data visualization and infographics. We decided to rearrange the course to capture the students' attention and 'buy-in' for the class by putting what they considered the 'easy' material upfront. We devoted 7 classes (about $25 \%$ of total class time) to understanding the need for good visualizations in data analytics, the theories that underlie effectively visualizing the data to communicate the information and insights we find through analysis, and ways to apply those theories to create compelling visualizations that communicate as precisely as possible the message we want to convey. The revised course set up is outlined in Table 3.

\section{FINDINGS}

The deep dive into visualization has been very popular with the students. We know from the level of student engagement in the class exercises, the quality of their homework submissions, their in-class presentations, and weekly assessments that these classes are stimulating the desire of the students to go beyond rote memorization to actually understanding and applying the information being presented. Because we devote so much time to this topic, students are also able to delve into the next three levels of Bloom's taxonomy - we ask them to analyze good and 
bad visualizations and then discuss characteristics of good versus bad visuals in small groups and again as a class. The students are then asked to evaluate a 'bad' visualization of their choice and transform it into a good visualization which covers both evaluation and creation in the taxonomy. We have found that the students are so interested in creating effective visualizations at this point, that they are eager to learn the tools (such as Excel and Tableau) that will allow them to create their own work product and then 'fix' it to communicate the story they found in the data as effectively as possible.

\section{Preview Complete}

This concludes the free, limited preview of this paper. Please buy full access.

\section{Citation Information}

McElfresh, Reed H., Laurie A. Branch and Todd Palmer. "Using Information Visualization to Generate Student Interest in Business Analytics: A Case Study." BRC Journal of Advances in Education 4, no. 1 (2020): 35-48. https://dx.doi.org/10.15239/j.brcadvje.2020.04.01.ja03

\section{Web APPE NDix}

A web appendix for this case is available at: https://dx.doi.org/10.15239/ j.brcadvje.2020.04.01.wa03 